\title{
Las reducciones jesuíticas de guaranies en el marco teológico jurídico de la Escuela Ibérica de la Paz
}

\author{
As reduções jesuíticas de Guaraníes no marco teológico jurídico \\ da Escola Ibérica da Paz
}

The Jesuit reductions of guaranies in the juridical theological framework of the Escuela Ibérica de la Paz

Bartomeu Meliàn

\section{RESUMEN}

Los abusos y crueldades cometidas por los conquistadores y colonizadores españoles en América fueron, desde época temprana, denunciados por otros españoles que mostraban una profunda consciencia crítica sobre tales eventos. La reflexión sistemática, y convergente, sobre los hechos referidos, llevada a cabo por parte de los teólogos y juristas de Universidades lusas y españolas dio lugar a una corriente de pensamiento que ha sido denominada "Escuela Ibérica de la Paz". Los jesuitas, fundadores de las reducciones del Paraguay, conocieron y tomaron para sí esta línea de pensamiento, buscando, además, ponerla en práctica. En torno a esto se constituiría aquello que frecuentemente fue entendido como el modelo utópico de las referidas misiones. Los escritos del primer Provincial jesuita del Paraguay, Diego de Torres Bollo, las Ordenanzas de Francisco de Alfaro y los Memoriales del padre Antonio Ruiz de Montoya, así como la asamblea indígena de Mbaracayú de 1630, confirmarían esa hipótesis.

Palabras-clave: Escuela Ibérica de la Paz. Jesuitas. Escritura. Misiones.

\section{ABSTRACT}

The abuses and cruelties committed by the Spanish conquerors and colonizers in America were, from an early age, denounced by other Spaniards who showed a deep critical awareness of such events. The systematic and convergent reflection on the referred facts, carried out by the theologians and jurists of Portuguese and Spanish Universities, gave rise to a current of thought that has been denominated "Escuela Ibérica de la Paz". The Jesuits, founders of the Paraguay reductions, knew and took this line of thought for 
themselves, seeking, in addition, to put it into practice. Around this would be constituted what was often understood as the utopian model of the aforementioned missions. The writings of the first Jesuit Provincial of Paraguay, Diego de Torres Bollo, the Ordenanzas of Francisco de Alfaro and the Memoriales of Father Antonio Ruiz de Montoya, as well as the indigenous assembly of Mbaracayú of 1630, would confirm this hypothesis.

Keyword: Escuela Ibérica de la Paz. Colonialism. Jesuits. Jesuit writings. Jesuits Missions.

RESUMO

Os abusos e crueldades cometidos pelos conquistadores e colonizadores espanhóis na América foram, desde muito cedo, denunciados por outros espanhóis, que mostraram uma consciência profundamente crítica sobre tais eventos. A reflexão sistemática e convergente por parte de teólogos e juristas de universidades espanholas e lusitanas sobre os fatos referidos, deu lugar a uma corrente de pensamento que tem sido chamada de "Escola Ibérica da Paz". Os jesuítas, fundadores das reduções do Paraguai, conheceram e tomaram para si esta linha de pensamento, procurando, ainda, coloca-la em prática. Em torno a isto se constituíram aquele que frequentemente foi entendido como modelo utópico das referidas missões. Os escritos do primeiro provincial jesuíta do Paraguay, Diego de Torres Bollo, as "Ordenanzas" de Francisco de Alfaro, e os "Memoriais" do padre Antonio Ruiz de Montoya, assim como a assembleia indígena de Mbaracayú de 1630, confirmariam esta hipótese.

Keyword: Escola Ibérica da Paz. Colonialismo. Jesuítas. Escritos. Missões.

Los intérpretes sociopolíticos de las reducciones con relativa frecuencia hemos ido a buscar lejos lo que estaba cerca; en la teoría lo que era pragmática; en la utopía, un lugar que ya había puesto los pies en el suelo. Pablo Hernández (1912) se preguntaba sobre las fuentes del régimen organizativo de esas Doctrinas, o Reducciones, examinando las que le parecían falsas o verdaderas. Para él las reducciones son el retrato de las Leyes de Indias pintadas por los jesuitas y devueltas vivas a la historia, y no tanto las Constituciones de la Compañía de Jesús o la planificación de una misión de conversión

La lectura que hicieron los jesuitas de las Leyes de Indias es de jesuitas con sus connotaciones, en las que se incorporan con fuerza el mundo guaraní y el Paraguay colonial. "Las reducciones jesuíticas de guaraníes constituyeron desde su inicio un sistema misional diferente" (MAEDER, 1999, p. 439).

Suelen pasarse por alto tres elementos decisivos de la misión jesuítica: el jesuita ha hecho la experiencia de los ejercicios espirituales de San Ignacio de Loyola, y el discernimiento, que es una sus principales claves de su acción; algunos de ellos habían pasado por la universidad, y en mayor o menor grado estaban dispuestos a escuchar y aprender en diálogo con los indios. Con estos tres principios y fundamentos básicos, una persona de buena voluntad, instruida 
en el pensamiento filosófico-jurídico de su tiempo podría llevar a término una acción que será colonial sin colonos, en contra del ambiente general de conquista y colonización que exterminaba a los Guaraníes mediante "pestilencias, malos tratamientos y guerras", según había denunciado el padre Alonso de Barzana en 1594 (FERNÁNDEZ GARCÍA, 1970, p. 590). Según el padre Marciel Lorenzana, en 1620, no quedaba sino una cuarta parte de los Guaraníes; si hubo utopía entre los jesuitas fue la de esperar contra toda esperanza.

De este modo las Reducciones guaraníes de jesuitas surgen y quedan integradas en un triángulo de influencias correlativas: el mundo guaraní, el mundo ibérico y el Paraguay de los siglos XVI y XVII. Estos factores configurarán un espacio de tensiones inevitables. Hay que advertir, sin embargo, que los actores de esa historia pasan a su vez por escenarios y escenas diferentes, aunque el drama colonial perdura y persiste como guión central.

\section{La Escuela Ibérica de la Paz}

El mundo ibérico había visto surgir en el siglo XVI una consciencia crítica respecto a la conquista y colonización, que mantendría bifurcado el camino de la historia en situación de contraste

Esa conciencia crítica vino expresada a través de personas de pensamiento convergente en la llamada Escuela Ibérica de la Paz, que dio origen al Derecho de Gentes, fundamento del Derecho Internacional vigente hasta hoy. En la medida en que este derecho fue asumido como universal, pudieron nacer otras experiencias históricas entre pueblos, siendo que alguna de ellas quedaría como patrimonio histórico de la humanidad.

La relación que se establece entre el marco teológico-jurídico proveniente de la Escuela Ibérica de la Paz y los jesuitas en sus misiones del Paraguay no es sólo una conjetura, aunque las citas textuales al respecto sean pocas.

La Escuela Ibérica de la Paz, como se la denomina hoy, pone de manifiesto que la conquista de América tanto por españoles como portugueses era ilegítima porque iba contra hombres y mujeres que tenían los mismos y más derechos a la vida y posesión pacífica de sus bienes que esos hombres venidos de afuera.

Esa Escuela tenía precedentes en la legislación española. Estaba el testamento de Isabel la Católica -en el que se subrayaba la total libertad del indígena-, las Leyes de Burgos de1512, dictadas durante la regencia de Fernando de Aragón, así como los decretos de 1520 reiteración de la libertad absoluta de los indios- y de 1526 sobre la penetración pacífica, 
durante la administración de Carlos I. La Leyes Nuevas de 1542 hablaban ya de la abolición de la encomienda.

\begin{abstract}
Sin embargo, los abusos de parte de los españoles continuaron - tal como lo demuestra la reiterada legislación-, como también las denuncias contra ellos y las Ordenanzas Reales para corregirlos; Domínguez Ortiz menciona una petición de 1542 a las Cortes en la que se solicitaba que se "mande remediar las crueldades que se hacen contra los índios [...] (FRÍAS, 2002, p. 324)
\end{abstract}

La Escuela Ibérica de la Paz hizo camino en la medida en que caminaba por él. La profecía es el sentido común dicho y vivido por adelantado, es pensar y hacer justicia desde el ahora presente.

\title{
Autores y textos
}

He aquí algunas de las sentencias que reflejan el pensamiento de sus autores más significativos, maestros que enseñaron en universidades españolas y portuguesas $\mathrm{y}$ misioneros que ejercieron su ministerio en las Américas españolas y portuguesas.

Francisco de Vitoria, o.p. (Universidad de Salamanca: 1526-1546)².

1.3 «[El título de descubrimiento] en sí mismo y aisladamente no justifica la posesión de aquellos bárbaros, ni más ni menos que si ellos nos hubieren descubierto a nosotros". (Relectio de Indias, Salmanticae, 1537-1538. I, 3, 2-3, p. 165

2. La naturaleza social del hombre: el hombre no es un lobo para el hombre 
«Va contra el Derecho natural que un hombre aborrezca sin razón a otro hombre. Pues no es el hombre un lobo para el hombre [...] sino hombre!». Relectio de Indias, Salmanticae, I, 3, 14-15, p.165.

4 «¿Con qué derecho?»: La duda sobre la legitimidad del dominio español sobre las Indias Occidentales

"Claramente, pues, se ve por todo lo dicho que cuando la expedición real se dirigió a las tierras de los bárbaros ningún derecho llevaba consigo para ocupar sus provincias». Relectio de Indias, Salmanticae, I, 2, 2-3, p. 165.

7.3. «Resulta pues esta conclusión cierta: que antes de la llegada de los españoles, eran ellos verdaderos señores, pública y privadamente». Relectio de Indias, Salmanticae, I, 1, 16, p.169.

Luis de Molina, s.j. (Universidad de Évora: 1568-1583).

La legitimidad de las soberanías indígenas

4.1 «La gracia y la fe perfeccionan la naturaleza, pero no la contradicen, por ello, si los hombres eran reyes antes de recibir la fe de Cristo [...], en virtud del poder conferido por la república, la cual lo posee por derecho natural, resulta evidente que al recibir la fe no pierden de ningún modo dicho poder y dominio, aunque se sometan al Sumo Pontífice al ingresar en la Iglesia». De Iustitia Et Iure, tomo I, liv. II, disp. XXVII, p. 283.

Francisco Suárez, s.j. (Universidad de Coímbra: 1597-1616).

2.2 «El poder de los príncipes cristianos, en sí mismo, no tiene una naturaleza mayor ni distinta del poder de los príncipes paganos; consiguientemente, en sí mismo, no posee otra materia ni finalidad». De Iustitia Et Iure, tomo I, liv. II, XII, p. 9.

Bartolomé de las Casas, o.p. (América Central, Venezuela, Perú y México: 1510-1547)3

5. La guerra justa por la libertad

"A lo que dice [Sepúlveda] que si bien se considera todo lo que yo digo y escribo va enderazado a probar que todas las conquistas que hasta ahora se han hecho han sido injustas

3 Las fechas se refieren al tiempo en el que ejercieron su ministerio en América. 
y tiránicas; digo, a lo primero, que dice su merced gran verdad, y así torno a redecir que todas las conquistas y guerras que desde que se descubrieron las Indias, hasta hoy inclusive, se han hecho contra los indios, fueran peores, y en ellas se han cometido más deformidades y con más ofensas a Dios que las que hacen los turcos y moros contra el pueblo cristiano". Controversia Con Sepúlveda. Valladolid, 1551, Réplica 12a:363.

José de Acosta, s.j. (Perú y México: 1571-1587)

2.2 «Difícilmente se han cometido jamás tantos y tan enormes crímenes por ningún pueblo bárbaro y fiero como por esos defensores del derecho natural y por los propagadores de la fe cristiana». Controversia Con Sepúlveda. Valladolid, 1551, II, IV, 5. p. 383.

Y consta por infinidad de testimonio que muchos más sin comparación han muerto en las guerras contra los indios que con ninguna tiranía de los bárbaros. ¿Qué cantidad de sacrificios y carnicería de indios no se llevó a cabo a causa del estrago provocado por la espada de los españoles». Controversia Con Sepúlveda. Valladolid, 1551, II, VI, 2-3. p. 387.

Antonio Vieira, s.j. (Brasil, Maranhão y Grão - Pará: 1632-1697).

1. La legitimidad de las soberanías indígenas

«...pues tiene la misma relevancia para la soberanía y la libertad, tanto la corona de plumas como la de oro, tanto el arco como el cetro». Voto sobre as Dúvidas dos Moradores de Sao Paulo (1694) ${ }^{4}$, in: Obras escolhidas, Lisboa, 1952, vol. V, pp. 341-342: 401.

\section{La dignidad del trabajo libre}

«Este pueblo, esta república, este Estado no se puede sostener sin los indios. ¿Quién nos traería un cubo de agua o un haz de leña? ¿Quién nos cavaría la tierra para la mandioca? ¿Lo harían nuestras mujeres? ¿Lo harían nuestros hijos? -Antes que nada, no son estos los aprietos en los que os quiero poner, como lo verán, pero cuando la necesidad y la conciencia obligan a tanto, digo que sí y vuelvo a decir que sí: que sus mujeres, que sus hijos y que todos nosotros nos mantengamos a nosotros mismos con nuestros brazos; porque mejor es mantenerse con el propio sudor que de la sangre ajena. ¡Ah, haciendas de Maranhão, si esos

4 Nota del Editor. El Padre Melià hace referencia a este trecho en castellano a pesar de indicar su ubicación en una obra editada en portugués. 
mantos y esas capas se retorcieran, habrían de escurrir sangre!!. ${ }^{5}$ Sermão ao Enterro dos Ossos dos Enforcados (1637), in: Sermões, Porto 1959, XIV, p.107: 405.

Las balizas principales de esa corriente de pensamiento son en términos generales:

- Todos los hombres son hombres para todos los demás.

- Ninguna conquista ni colonización anula el dominio que tienen los pueblos sobre sus bienes, de los cuales son soberanos.

- Ni el emperador ni el papa ningún derecho tienen para entrar en tierras ajenas ni retirarles a sus posesores la soberanía. Conquista y colonización son ilegítimas.

- Ni la infidelidad religiosa ni los vicios, con tal de que no sean acciones contra terceros inocentes, justifica actos de conquista ni enajenación de dominio. Se trata de un derecho universal cuyo sujeto es la humanidad entera.

Años después las Ordenanzas de Felipe II (1573) actualizaron la Leyes Nuevas de Indias, promoviendo la entrada pacífica de los misioneros a los territorios todavía no descubiertos, quedando frenada la conquista por las armas, aunque no enteramente desterrada.

Es en este escenario teológico jurídico, en un Paraguay en el que seguía todavía vigente y con la fuerza de la mala costumbre el sistema de la encomienda, donde los jesuitas fundarán en los inicios del siglo XVII las Reducciones de Guaraníes.

\section{Ecos de la Escuela Ibérica de la paz en los jesuitas del} Paraguay

La lectura que hacen los jesuitas de los teólogos-juristas de la Escuela Ibérica de la Paz no siempre es directa ni textual, pero se adivinará su eco en las instrucciones programáticas con que comenzaron las Reducciones y en las denuncias y alegatos con que las protegerán y defenderán mediante un recurso continuo al espíritu y letra de la legislación española vigente que tenían sus raíces en el campo fecundo de sus principios y doctrinas.

5 Nota del Editor. El Padre Melià hace referencia a este trecho en castellano a pesar de indicar su ubicación en una obra editada en portugués. 
Indagaré la presencia de la Escuela Ibérica de la Paz en dos jesuitas, que tuvieron una marcada influencia en el principio, desarrollo y defensa de las Reducciones del Paraguay.

2.1. Diego de Torres Bollo (1551-1638): la libertad de los indígenas.

Jesuita desde 1571, estudió teología en Valladolid y fue destinado a la muy extensa misión de la 'provincia' jesuítica del Perú. Trabajó en la misión de Juli junto al lago Titicaca donde convivían con el pueblo aymará otros grupos andinos, cada uno con su iglesia. Su vuelta a Europa como procurador de la Provincia jesuítica del Perú durante los años 1601-1604 le puso en contacto directo con personajes imbuidos por el espíritu del todavía reciente Concilio de Trento (1545-1563), como el cardenal de Milán, Federico Borrromeo, con quien sostuvo una amistad de sinceras consultas y fecundos proyectos.

Contrariamente a lo repetido por una abundante historiografía, esas reducciones jesuíticas no son una excepción colonial - una utopía a pesar de la colonia -, sino tal vez la versión mejor conseguida de un colonialismo político religioso, que alcanza un alto grado de legitimidad al hacer posible en su seno la corrección de los abusos y de las injusticias que ya se consideraban inherentes al colonialismo como tal. El desafío fue hacer política colonial sin colonos. Los jesuitas nunca dejaron de pensar que su misión era reducir a las poblaciones guaraníes "a vida política y humana", que por cierto no podía llevarse a cabo sin vida cristiana. Ahí estaba la extraña mezcla de cabeza de oro y pies de barro; utopía y realismo pragmático.

El pensamiento que sustenta la acción de Torres Bollo se expresará de modo significativo en cuatro planos:

- el Memorial de 1603,

- - las Instrucciones para las misiones del Guayrá (1609) y Paraná (1610), las Cartas Anuas enviadas a Roma en los años de su provincialato (1607-1615).

-- y de forma indirecta las Ordenanzas de Alfaro (1612).

\section{El Memorial de 1603}

Antes de ser creada la provincia del Paraguay en 1604, el padre Torres Bollo, a partir de sus experiencias misioneras - había estado en Juli, Cuzco, Quito y Potosí- ya había escrito un Memorial dirigido al presidente del Consejo de Indias, don Pedro Fernández de Castro que 
está datado - casi con seguridad- en Valladolid en diciembre de 1603, apenas conocido hasta que fue editado en tiempos recientes (FERNÁNDEZ GARCÍA, 1986, p. 458-482).

Este Memorial es la síntesis de la experiencia acumulada en sus recorridos, pero es, también, la prefiguración de la labor futura; es una denuncia respecto de los abusos contra los indios, que él mismo ha constatado, pero es a la vez una propuesta concreta sobre el modo de evitarlos (FRÍAS, 2002, p. 326).

En este Memorial el padre Torres examina la colonia española desde la perspectiva de la libertad: no puede justificarse una forma de civilización que anula la libertad de aquel a quien se quiere civilizar.

El tercer agravio que reciben [los indios] en sus servicios es andar siempre apartados de la doctrina y de sus mujeres, con que se impide por una parte el fruto y bien espiritual de sus almas y por otra la propagación y generación de sus hijos. Esto se ve en las minas, en los trajines, servicio de ciudades, trapiches, obrajes y viñas; en todo lo cual andan apartados de sus mujeres y es toda la vida, sin que los dejen respirar ni hacer sus chácaras (FERNÁNDEZ GARCÍA, 1986, p. 470).

La preocupación real de los jesuitas por lo que ellos entendían ser la libertad de los indios y su liberación del servicio personal fue una constante, en todo el primer período fundacional de las Reducciones. El provincial de los jesuitas era un anti-encomendero convencido y un decidido defensor de la libertad absoluta de los indios. Para él reducción y encomienda se anulaban mutuamente.

Frente al problema del servicio personal existían dos tipos de mentalidad: una, simplemente reformista que apelaba a la conciencia moral de los encomenderos y los llamaba a obrar en conciencia y no abusar del trabajo indígena; la otra, más radical y efectiva, quería la supresión de todo servicio personal lo que implicaba de hecho la desaparición del sistema de encomienda y hasta le sustraía las condiciones de posibilidad. La dignidad del indígena pasa por su necesaria libertad.

En esta ecología ética coincide con la de la Escuela Ibérica de la Paz. 


\section{Las Instrucciones para los misioneros del Guayrá y del Paraguay}

La experiencia del padre Torres Bollo de la reducción peruana de Juli, que tuvo que funcionar a pesar de la encomienda, lo había convencido de la necesidad de librarse de dicho régimen.

Para ello podía echar mano de varios instrumentos legales, como era una carta del rey a Hernandarias, de 5 de julio de 1608 (PASTELLS, 1912, p. 139), en el sentido de que: "los indios que se convirtieren por el evangelio se pongan en su real corona y por 10 años no paguen cosa alguna" (CA, 1927, p. 40).

Esas Instrucciones fueron felizmente transcritas en su totalidad por el historiador jesuita Pedro Lozano. La primera es la Instrucción del padre provincial para los padres Joseph Cataldino y Simón Mascetta, quienes salen de la Asunción para emprender la conversión de los infieles del Guairá y se refiere lo que obraron en el camino (LOZANO, 1755, p. 136-141).

Para el padre Diego Torres sin duda "la primera regla de las misiones es alcanzar de Nuestro Señor una grande estima de la gloriosa empresa que les ha encomendado y hacerse aptos instrumentos suyos, para la conversión de tantos infieles." (LOZANO, 1755, p.136).

Para esos misioneros un paso esencial, muy olvidado en nuestro tiempo que tanto se jacta de haber descubierto la interculturalidad, será "deprender [aprender] y estudiar la lengua guaraní, y ejercitarla con los indios”. (LOZANO, 1755; MELIÀ, 2004, p. 89-97).

\footnotetext{
En treinta años de experiencia de Indias, he hallado que nunca los nuestros aprenden las lenguas de los indios ni les cobran amor si no es estando entre ellos. Y faltándoles la lengua y la aplicación, como faltan a la gracia de la vocación... andan inquietos y se vuelven a España o salen de la Compañía. (CA, 1927, p. 78).
}

El aprendizaje de las lenguas era para él un punto central. Y en la Segunda Instrucción, con mayor puntualidad explicaba que, a saber la lengua: "[...] se atienda con sumo cuidado siempre, no se contentando con saberla como quiera, sino con eminencia: persuadiéndose que depende en segundo lugar de ello la conversión de los índios [...]" (LOZANO, 1755, p. 248). 
Hay en toda la Instrucción una serie de importantes prescripciones y consejos que apuntan a crear un nuevo espacio cultural y religioso, autónomo aun dentro de cuadro de las leyes españolas y en relativa continuidad con el modo de ser guaraní.

El pueblo se trace al modo de los del Perú, o como más gustaren los indios, y pareciere al Licenciado Melgarejo, con sus calles y cuadras, dando una cuadra a cuatro indios, un solar a cada uno y que cada casa tenga su huertezuela y la iglesia y casa de VV.RR. en la plaza, dando a la iglesia y casa el sitio necesario para cementerio y la casa pegada a la iglesia, de manera que por ella se pase a la iglesia haciendo esto poco a poco y a gusto de los indios, habiendo ellos hecho primero sus casas y una pequeña para VV.RR. y una enramada para decir misa que sirva (LOZANO, 1755, p. 138).

En los escritos de Torres se insiste repetidamente en la necesaria consulta a los indios, sobre todo cuando se trata de la elección de un lugar para la Reducción:

[...] hagan la reducción y población, como por ventura será en la boca de la Tibaxiva o cerca, advirtiendo primero, que tenga agua, pesquería, buenas tierras y que no sean todas anegadizas, ni de mucho calor, sino buen temple y sin mosquitos, ni otras incomodidades y en donde puedan sembrar y mantenerse hasta ochocientos o mil indios, en lo cual ellos mismos darán el mejor parecer $\left[n^{\circ} 7\right],[\ldots]$ haciendo esto poco a poco y a gusto de los indios [n ${ }^{\circ}$ 8] (LOZANO, 1755, p. 138).

En esta actitud viene reconocida la validez del sistema guaraní, y especialmente su forma de gobierno. Aunque más tarde se crearán nuevas estructuras y oficios, que provienen de las Leyes de Indias -por ejemplo, una forma de gobierno municipal con corregidores, cabildantes, alféreces, secretarios, fiscales y otras cargos, que suponen significativas trasformaciones respecto al sistema indígena-, no se pretende una ruptura con lo anterior; y así será mantenido hasta el final el régimen de caciques, que de hecho continuarán siendo la instancia de mayor autoridad y la más crítica en situaciones graves. "Enseñándoles las obligaciones de su oficio, y que el fiscal haga el suyo con prudencia, entereza y suavidad, y a los indios el respeto y obediencia que han de tener a los padres sacerdotes y a los suyos naturales y a los caciques y fiscales" (LOZANO, 1755, p. 139-140). El gobierno de los pueblos adoptará de este 
modo un cierto bilingüismo político, reflejado incluso en los préstamos del castellano para designar las nuevas funciones.

La segunda Instrucción del padre Provincial Diego de Torres para los padres que están ocupados en las Misiones del Paraná, Guairá y Guaicurús (LOZANO, 1755, p. 248-252) tiene un carácter más general y extensivo. Desde el punto de vista antropológico llama la atención el tratamiento genérico de los indios, como si ellos constituyeran un todo uniforme, cuando en realidad lo genérico es la colonia como tal y el proyecto político de civilización pensado para todos como un todo; pronto se manifestaría la diferencia radical entre los pueblos guaraníes, agricultores y aldeanos, y los guaycurús, cazadores y dispersos por las pampas chaqueñas.

La redacción de la segunda Instrucción contiene las mismas directrices que la primera, pero con secuencia con acentos distintos. Hay que atender a saber la lengua, "no contentándose con saberla como quiera, sino con eminencia [...] y hablar siempre en ella" (LOZANO, 1755, p. 248).

Siendo un objetivo principal de la Instrucción poner la base de una Reducción, que se pretende sea el nuevo tekoha común de varias aldeas y varios caciques, lugar y espacio de un nuevo ser, de "un somos lo que somos" transformado y duradero, la consulta a los caciques y a los indios es fundamental.

Antes de fundar el pueblo, se considere mucho el asiento de él, que sea capaz para muchos indios, de buen temple, buenas aguas a propósito para tener sustento, con chacras, pescas y cazas, en lo cual se deben informar muy despacio de los mismos indios, principalmente de los caciques, teniendo atención de que estén apartados de otros con quien traigan guerras. Funden el pueblo con traza y orden de calles y dejando a cada indio el sitio bastante para su casilla y huertezuela (LOZANO, 1755, p. 249).

Lozano (1755, p. 141) comenta que estaban "estas Instrucciones concebidas con cabal comprensión de las materias, sólida prudencia en las disposiciones y próvida cautela de los males y peligros". Todo esto proviene de experiencias bien asimiladas y un pensamiento arraigado en la mejor tradición teológico jurídica del momento. La exitosa misión de Juli del Perú no es copiada, pero sin duda recordada. 


\title{
La cuestión de la encomienda
}

No hay indicaciones de que se quiera romper de entrada con los españoles, pero se mantiene con firmeza que el sistema de encomienda no puede prevalecer sobre el derecho a la libertad del indígena. Los colonos españoles no tienen ningún derecho sobre el trabajo indígena que es dominio esencial del ejercicio de su libertad. El territorio guaraní en el área donde van a trabajar los jesuitas no estaba todavía del todo invadido -y no lo estaría hasta bien entrado el siglo XX-, aunque los españoles de Ciudad Real y Villarrica ya reclamaban la encomienda de sus indios. Así el padre Torres, vuelve a insistir con mayor fuerza y concreción en el modo como deberán proceder los misioneros con los españoles en general y con los encomenderos en particular.

En la primera Instrucción ya se habla del peligro español.

\begin{abstract}
Con todo el valor prudencia y cuidado posible se procure que los españoles no entren en el pueblo y si entraren que no hagan agravios a los indios y salgan con brevedad y en ninguna manera les dejen sacar piezas, y en todo los defiendan, como verdaderos padres y Protectores; $y$ séanlo de toda la comarca y de manera que todos los indios lo entiendan (LOZANO, 1755, p. 140).
\end{abstract}

En la segunda Instrucción, al encarar un escenario más amplio es también más explícito, pues tiene en perspectiva situaciones muy diversas y con historias diferentes, pero todas ellas ya están amenazadas por los falsos derechos y exigencias que los encomenderos reclaman desde el pasado 1556, cuando un ya débil Domingo de Irala consintió en dar mercedes de encomienda. "Con los españoles se proceda con toda prudencia, procurándolos ganar a todos, así por el bien de sus almas, como porque no nos impidan y hagan daño a los indios y los agravios sean menos; pero entiendan también, que no los consentiremos y que por lo mismo avisaremos a quien lo remedie". (LOZANO, 1755, p. 251).

En este punto es donde hay mayor convergencia con la escuela Ibérica de la Paz. Torres es un misionero, como Bartolomé de las Casas, como Manuel de Nóbrega en Brasil y José de Acosta en Perú, testigo de vista de los males y abusos que denuncia.

Torres no era sólo teólogo y jurista, sino misionero y gobernante que sabe que la idea sólo adquiere su pleno valor cuando es traducida en la práctica. La determinación de la 
Congregación provincial que tuvo lugar en Santiago de Chile en 1608, de quitar el servicio personal de los indios que servían en el colegio, fue aplicada al momento.

[...] ninguno de los hombres ha sido admitido hasta ahora en confesión por no querer arreglar su comportamiento con los indios. Sin embargo, ya comienzan a volver en sí, especialmente después de la visita del Oidor de la Audiencia, y algunos por miedo humano, otros por temor de Dios, entran en arreglos justicieros con los indios encomendados, $y$ restituyen los daños causados a ellos (CA I, 1927, Anua de 1614, p. 405).

No es de extrañar el revuelo que causó el hecho de que los jesuitas dieran libertad a los indios que estaban a su servicio; su "mal ejemplo" resultó insoportable. La primera expulsión de los jesuitas de su colegio de Asunción, en 1612, fue motivada por la presión de los encomenderos que no aceptaban la defensa que los jesuitas hacían de la libertad de los indios (MELIÀ, 1997, p. 220-223). Que por lo menos se callasen en sus prédicas.

Los jesuitas permanecieron firmes. El padre Roque González de Santa Cruz en los mismos años mantuvo esta posición en términos aún más radicales, como lo manifiesta en la carta a su hermano: "De mí digo que no confesaré a ninguno por cuanto tiene el mundo, porque han hecho el mal y aun reconocerlo no quieren” (BLANCO, 1929, p. 545).

El desentendimiento de jesuitas y el grupo de españoles que formaban el grupo de encomenderos, nunca cesó; no sin sorna decía un jesuita de la época que la ciudad de Asunción los quería a los jesuitas como "al dolor de vientre". Con Alfaro, como veremos, esta práctica pasó a legislación.

\section{Las Ordenanzas de Francisco de Alfaro}

Las Ordenanzas de Felipe II en 1573 al insistir en la "conquista espiritual" y desmarcarse de la conquista por las armas propugnaban un viraje notable y nuevo soporte político a la acción de los españoles en el Nuevo Mundo (ZAVALA, 1977, p. 40-42). Pero faltaba mucho camino por recorrer y sobre todo los hombres que quisieran y pudieran recorrerlo. 
La visita del oidor Francisco de Alfaro pretendía llevar a cabo lo que estaba mandado y no había manera de hacer cumplir, que era "desagraviar a los indios" y "poner las cosas en razón"; y concretamente acabar con el servicio personal y mejorar las condiciones de vida y de trabajo de los indios (FRÍAS, 2002, p. 327).

El presidente de la Audiencia de Charcas comisionó a Don Francisco de Alfaro a visitar las provincias de Tucumán, Cuyo, Buenos Aires y Paraguay, con el propósito de enterarse sobre el buen funcionamiento de las encomiendas. La visita no se limitó a recoger pareceres de gente notable en las ciudades, sino que recorrió los caminos de la inmensa región que la Audiencia de Charcas le había asignado y confiado y duró varios años.

El historiador jesuita Pedro Lozano (1755, p. 301) se hace eco del consejo y dirección que el padre provincial y el padre Marciel de Lorenzana habían ejercido sobre Alfaro. Para ellos, y para la Compañía de Jesús, la Reducción era una alternativa, siempre y cuando permitiera salvaguardar la libertad de los indios. Los pueblos de indios regidos por el clero secular y por los franciscanos -incluso la primera reducción jesuítica de San Ignacio Guasú- - tuvieron que acomodarse el régimen de encomienda, que apenas pudieron mitigar con medidas de control y prevención de abusos. La política adoptada frente al servicio personal marca la diferencia y la asimetría entre los diversos tipos de reducción en el Paraguay, más concretamente entre franciscanos y jesuitas (MAEDER, 1995).

Según Torres, en carta al padre general, Alfaro ponía los medios humanos y políticos para quitar el servicio personal en aquellas gobernaciones -especialmente las de Tucumán, Chile y Paraguay- que era el gran estorbo para la salvación de españoles e indios y conversión de los infieles, mientras que la fundación de la provincia jesuítica del Paraguay aportaba los medios espirituales y religiosos para completar una acción de tanta importancia. Alfaro y los jesuitas eran las dos manos de una tarea común, diferente en sus medios pero única en su fin.

Cuando el 11 de octubre de 1611, Alfaro dió en Asunción sus famosas Ordenanzas, explica que no decide algo nuevo, sino que ejecuta el derecho antiguo fundado en derecho común y natural -y ahí resuena claramente el eco de la escuela salmantina e ibérica de la paz, que tanto habían influenciado la Leyes Nuevas de 1542. Su visita, comenzada en 1608 le hizo ver por sus propios ojos "el mal uso que ha habido de la parte de los gobernadores y en el mal modo de las encomiendas que han hecho, como de parte de los vecinos en el exceder en usar del servicio de los indios" (ZAVALA, 1977, p. 260). De hecho, el servicio de los indios había derivado en esclavitud abierta y genocidios olvidados. La lista de violencias y abusos observados y constatados es larga y vergonzosa. El Paraguay, incluso en comparación con otras partes de América, "se representa en el encuentro más brusco entre el marco institucional [...] y los usos peculiares de la gobernación del Río de Plata" (ZAVALA, 1977, p. 262). Ya entonces se había instalado un costumbro, que después pretenderá hacerse pasar por marca de identidad paraguaya de dejar pasar las cosas como están y que no es sino la aceptación de la injusticia e impunidad de la clase dominante sobre los pobres indefensos. Un resumen de los 85 capítulos 
de esas ordenanzas se puede ver en la obra Orígenes de la colonización del Río de la Plata (ZAVALA, 1977, p. 260-287). Las reacciones de los colonos eran previsibles y en las ciudades del Río de la Plata comparables a las que se dieron en Asunción, como se ha visto. A pesar de resistidas, ellas fueron aprobadas por el Rey en el año 1618 y años después se incorporaron a la Recopilación de la Leyes de Indias, de 1680. Por entonces el proyecto misionero de los jesuitas ya contaba con significativas y admiradas realizaciones y por contraste era testimonio real de que los colonos, al procurar su riqueza con el servicio personal de los indios, producían pobreza para sí mismos y miserias ajenas.

\section{Antonio Ruiz de Montoya (1585-1652) y sus Memoriales}

Tal cual fray Antonio de Montesinos y fray Bartolomé de Las Casas, el marco al que apela el padre Antonio Ruiz de Montoya para denunciar y remediar los crímenes que contra los indios Guaranís se han cometido y cometen en el Paraguay, es, además de la concepción cristiana de la vida, el derecho natural y las Leyes de Indias, y aun la recta conciencia del rey y del Consejo de Indias. Su actuación se desarrollará en tres escenarios de un mismo guión: las Reducciones del Paraguay, Paraná, Uruguay y Tape (1612-1637), la corte de Madrid (16381643) y gestiones en Lima, donde morirá (1643-1652).

El padre Antonio Ruiz de Montoya había nacido en Lima en 1585. A los 17 años ciñó espada de caballero. Dirá de sí mismo que fue "más profano que los gentiles, esclavo de vanidades y adorador de Venus". Había dejado los estudios y se envolvió con sucesos que le merecieron cárcel y condena de destierro; algo más, pues, que travesuras de muchacho irresponsable. Hirió y fue herido. Pero se arrepintió de esa vida de vicios y excesos, volvió a los estudios y en 1606 entró al noviciado de los jesuitas. En 1612, de camino hacia el Paraguay era ordenado sacerdote, después de una preparación teológica brevísima. Pero no hace ningún curso universitario; "fue una lástima quitarle los estudios", lamentarán los mismos jesuitas. Ya en su nuevo destino trabajaría en las recién fundadas Reducciones del Guayrá, siendo el mismo fundador de otras diez entre 1625 y 1628.

Dedicado al estudio sistemático de la lengua guaraní, la llegó a dominar de manera notable, como lo atestiguan los cuatro volúmenes publicados en Madrid en 1639-40: Tesoro (diccionario fraseológico), Arte (gramática), Vocabulario y Catecismo de la lengua guaraní. De hecho, son todas ellas obras bilingües. 


\section{La asamblea de los trabajadores de la yerba mate - la yerba del diablo- (1630)}

La lucha contra el servicio personal y la denuncia contra los abusos de los encomenderos, en los cuales vemos la aplicación de los principios y dictámenes de la Escuela Ibérica de la Paz, no estaba solamente representada por la voz del provincial Diego de Torres, sino que era compartida por los jesuitas del Paraguay, los del colegio y los de la reducciones. Era el aire que se respiraba entre ellos.

Cansados de las prácticas abusivas de los encomenderos que hacían trabajar a los indios en los yerbales, los jesuitas que estaban en el Guayrá promovieron una gran junta o asamblea para hacer conocer a los indios sus derechos tan sistemáticamente conculcados por sus patronos y que el rey los declaraba libres del servicio personal.

De este documento se pueden entresacar frases y párrafos que muestran la coincidencia del concepto de libertad predicado por los jesuitas y el sentir de los Guaraníes al respecto. Éste es el primer texto en lengua guaraní que se tiene registrado por escrito.

Es por eso por lo que queremos que vosotros mismos hagáis escuchar, por favor, nuestras palabras al Rey. No hay otro que vaya a tomar cuidado de nosotros, no hay escribano, y aunque lo hubiera, no lo va a querer hacer de ninguna manera, o hará sentir sus propias palabras, diciendo sin ninguna razón que esas son palabras de indio [de Mbyá]. (MONTOYA, 1630 apud MCDA, 1951)

Es particularmente dramática la certificación del padre Antonio Ruiz de Montoya:

"Ha veinte años que veo estas y peores cosas de agravios de Indios que fuera (si se hubieran de referir) hacer una larga historia principalmente en materia de Mbaracayú y su infernal yerba" (MCDA, 1951, p. 360).

En la Conquista Espiritual, en referencia al mismo asunto, dirá Montoya que:

[...] tiene la labor de esta yerba consumidos muchos millares de indios; testigo soy de haber visto por aquellos montes osarios bien grandes de 
indios, que lastima la vista el verlos, y quiebra el corazón saber que los más murieron gentiles descarriados por aquellos montes en busca de muchas sabandijas, sapos y culebras, y como aún de esto no hallan, beben mucha de aquella yerba de que se hinchan los pies, piernas y vientre, mostrando el rostro solos los huesos, y la palidez la figura de la muerte (MONTOYA, 1989, p. 63).

\section{Armas para la libertad}

La lista de esos Memoriales, establecida por Hugo Storni (1984), muestra hasta qué punto Montoya ha captado la situación política y laboral de los indios, y cuánto importa su solución, no solo para las Reducciones sino para los intereses de la corona española en América en términos de derecho y de geopolítica. Sus alegatos van dirigidos a asegurar enteramente la libertad de los indios y protegerlos contra las injusticias y abusos, dándoles los instrumentos necesarios para que ellos mismos se defiendan y protejan, incluso armas de fuego, que, dados los extremos a que se ha llegado de ataques y capturas de miles de indios de las Reducciones sobre todo en el Guayrá, parecían necesarias. No se pretendía formar un ejército sino salvaguardar la libertad de los indios, aunque el resultado fue la formación de un cuerpo militar estable que resultó en beneficio de los intereses de la corona española en la región. ${ }^{6}$

Los tres primeros memoriales impresos en Madrid, distribuidos apenas como instrumentos de trabajo a los miembros del Consejo de Indias y autoridades pertinentes, aunque editados, mantienen un cierto carácter de manuscritos, por su finalidad de uso y por los pocos ejemplares ahora conservados.

[..] y enseña el derecho que decide que no hay prescripción contra la libertad: leg. Última. Cod. Longi temporis presciptio. Quae pro libertate leg. Usucapionem, ss de usucapione, §. Sed aliquando, instit, eodem título, \& lege 6 num. 29. Part. 3 \& docet Molina tom. 2. De iustitia tractat.

6 La cuestión de poner a los indios en armas para su propia defensa, fue objeto de repetidas y sin duda acaloradas discusiones entre los mismos jesuitas, algunos de los cuales no veían poder compaginar su uso con el espíritu evangélico de paz que predicaban conforme al evangelio, mucho menos que un jesuita fuera su comandante. Hasta hoy el tema está sujeto a pareceres encontrados, tanto más que el ejército guaraní de las Misiones tuvo que actuar más bien en defensa de los intereses geopolíticos de la corona española, con muchas consecuencias negativas para la población indígena que tenía que ausentarse durante largos tiempos de sus trabajos ordinarios e incluso era ocasión de muchas fugas y desamparo de sus familias. La película La Misión (1986) de Ronald Joffé, con Jeremy Irons y Robert de Niro, en su momento, actualizó la problemática. 
2. Disputat. 79. Column. 471. § liber homo. Por ser contra el derecho natural, \& habetur C. flagitia 32 q. 7. (MONTOYA, Memorial de 1638, fol. 2v, In: Melià 1985).

Acude también a las Bulas de Paulo III y Clemente VIII

[...] en las cuales se declara, no poder ser cautivos los indios, ni privados de sus bienes, mujeres e hijos, aunque sean infieles, so graves penas contenidas en las dichas Bulas, reservada la absolución a la Santa Sede Apostólica, como lo repara Manuel Rodríguez en sus cuestiones regulares, tom. 2. Quaest. 99. Att. 4. en donde de paso se note lo que notó este autor: circa quam concesionen nihil venit notandum, sed plorandam cum oculis nostris tot millia indorum devastata, eorumque terras propris dominus privatas cernamus, quod plus ad lachrimas compellit est, quod bec facta sunt a Christianis Regnum (bristi publicantibus contra voluntatem Papae, Regul Hipaniarum, las cuales Bulas trae doctísimamente el Doctor don Juan de Solorzano en el tomo que hizo de Indiarum iure lib. 2. c.8. n. 79. \& lib. 3. C. 7. N. 55. Vers. Quod ut melius, remitiendo Su Majestad la ejecución a la persona que quiere servido para que tenga este punto su efecto.

Habla no de oídas, sino por vista de ojos, que han tenido que soportar el horroroso espectáculo de indios ya cristianos atacados desde el doble frente de españoles encomenderos y portugueses "bandeirantes paulistas", que alzan la bandera para incursionar en territorio guaraní y llevarse a la población ya misionada como esclavos. En los dos casos se trata de privación de libertad, de trabajo esclavo y exilio forzado. Hay que decir que aún hoy, son los derechos humanos indígenas negados con más frecuencia, junto con la usurpación de sus territorios, convertidos en objeto de especulación monetaria y lugares de sufrimiento y muerte.

Llama la atención en el mismo hombre la orientación mística y el realismo práctico para enfrentar situaciones económicas y políticas en las que se verá envuelto a lo largo de toda su vida. El hombre espiritual nunca dejó de pisar tierra; será sacerdote, político y profeta de utopías.

La singularidad de la experiencia reduccional de los jesuitas en el Paraguay se ha hecho depender de extrañas y externas utopías, hemos dicho. Lo que es una verdadera utopía es la 
de una sociedad que es capaz de hacer realidad en su vida las leyes del propio país en el que vive. El evangelio y la doctrina que van a predicar se dan por supuestos, así como las propias constituciones de la Compañía de Jesús que rigen su vida y misión. Pero concretamente los jesuitas manifestarán una oposición radical al sistema de la encomienda, aunque en algún caso, como veremos, tuvieran que admitirla.

Guiarse por las leyes y procurar los medios para que ellas tengan efectiva vigencia es ya una utopía. ¿Por qué caminos lo habrían logrado los jesuitas del Paraguay? ¿Hasta qué punto habrían conocido los padres de la Reducciones el pensamiento de esa Escuela Ibérica de Paz? Si lo conocieron, ¿se puede pensar que pretendían llevarlo a la práctica haciéndolo salir de las aulas universitarias y del papel? Con todo eso, dada la colonialidad en que estaban inscritas las Reducciones, todavía nos inquieta la clarividente sospecha de indio Potyrava ${ }^{7}$, cuando incitaba a Ñesú a no dejarse reducir, ni siquiera por los jesuitas. Este estado de "disimulado cautiverio". Pues, ¿por qué consientes que nuestro ejemplo sujete a nuestros indios y lo que es peor a nuestros sucesores, a este disimulado cautiverio de reducciones de que nos desobligó la naturaleza?" (BLANCO, 1929, p. 525).

Aun sabiéndose dentro del mundo colonial, los jesuitas se empeñaron en crear un espacio de libertad posible que por otra parte no era sino poner en práctica la legislación española, impregnada con los principios de la Escuela Ibérica de la Paz, en consonancia con el ideal guaraní de una tierra donde es posible el buen vivir.

\section{Referências}

BLANCO, José María. Historia documentada de la vida y gloriosa muerte de los Padres Roque González de Santa Cruz: Alonso Rodríguez y Juan del Castillo, de la Compañía de Jesús, mártires del Caaró e Yjuhí. Buenos Aires: De Amorrortu, 1929.

CA. Cartas anuas de la provincia del Paraguay, Chile y Tucumán, de la Compañía de Jesús. Buenos Aires: Talleres Casa Jacobo Peuser, 1927

FRÍAS, Susana R. La dignidad del indígena en los escritos de Diego de Torres. Anuario del CEH, [S. 1.], n. 2, año 2, p. 321-336, 2002.

7 Nota del Editor. Potyrava, también consignado en los registros documentales como Potirava, del guaraní 'el destinado a ser flor', fue un prestigioso cacique guaraní que se rebeló contra su Corregidor en el Pueblo de San Francisco Javier. Este hecho aparece relatado en la Historia de la Provincia del Paraguay de la Compañía de Jesús, escrita por Nicolás del Techo. Madrid. 1897. 5 Tomos. 
HERNÁNDEZ, Pablo. Un misionero jesuita del Paraguay en la Corte de Felipe IV. Razón y Fe, Madrid, v. 33, p. 71-79, 1912.

LOZANO, Pedro. Historia de la compañía de Jesús en la provincia de Paraguay. Madrid, 1755.

MAEDER, Ernesto J. A. Asimetría demográfica entre las reducciones franciscanas y jesuíticas de guaraníes. Revista Complutense de Historia de América, Madrid, n. 21, p. 71-83, 1995.

MAEDER, Ernesto J. A. La Iglesia misional y la evangelización del mundo indígena. In: ACADEMIA NACIONAL DE LA HISTORIA. Nueva historia de la nación argentina. Buenos Aires: Planeta, 1999. p. 433-468.

MCDA. Manuscritos da coleção de Angelis: I: jesuítas e bandeirantes no Guairá (1594-1640). Rio de Janeiro: Biblioteca Nacional, 1951.

MELIÀ, Bartomeu. Assembléia guaraní de 1630 denuncia exploração através do plantío da erva infernal. Porantim, Brasília, n. 39, p. 6, 1982.

MELIÀ, Bartomeu. El guaraní conquistado y reducido. 4. ed. Asunción: CEADUC-CEPAG, 1997.

MELIÀ, Bartomeu. Escritos guaraníes como fuentes fundamentales de la historia paraguaya. Iberoamericana Pragensia, Praga, año 38, p. 85-109, 2004.

MELIÀ, Bartomeu. Los dos primeros memoriales de Montoya en Madrid. In: Anais do VI Simpósio Nacional de Estudos Missioneiros. Santa Rosa: Faculdade de Filosofia, Ciências e Letras Dom Bosco, 1985. p. 85-89.

VITORIA, Francisco de. Relectio de Indis. Madrid: Salmanticae, 1537-1538.

MONTOYA, Antonio Ruiz de. Conquista espiritual hecha por los religiosos de la Compañía de Jesús em las Provincias del Paraguay, Paraná, Uruguay y Tape. Estudio preliminar y notas de Ernesto Maeder. Rosario. Equipo Difusor de Estudios de Historia Iberoamericana [1639] 1989.

FERNÁNDEZ GARCÍA, Enrique. Monumenta Peruana. Roma: Institutum Historicum Societatis Iesu, 1970. Tomo V.

FERNÁNDEZ GARCÍA, Enrique. Monumenta Peruana. Roma: Institutum Historicum Societatis Iesu, 1986.

PASTELLS, Pablo. Historia de la compañía de Jesús en la provincia del Paraguay. Madrid, 1912.

STORNI, Hugo. Antonio Ruiz de Montoya (1585-1652). Roma: Archivum Historicum Societatis Iesu, 1984. p. 425-442.

ZAVALA, Silvio. Orígenes de la colonización en el Río de la Plata. México. Editorial de El Colegio Nacional. 1977.

Recebido em 27/03/2018

Aprovado em 10/04/2018 